\title{
IMPLEMENTATION STRATEGIES FOR THE GUIDELINES FOR THE EARLY DETECTION OF BREAST CANCER IN BRAZIL
}

\author{
Estratégias de implementação das diretrizes para \\ a detecção precoce do câncer de mama no Brasil
}

\author{
Sandra Marques Silva Gioia* (D), Silvio Fernandes da Silva1 (iD)
}

\section{ABSTRACT}

This research project aimed to identify strategies for implementing guidelines for early detection of breastcancer in Brazil. Regarding the specific objectives, it aimed to identify studies in the specialized literature on the difficulties and strategies for implementing the guidelines for early detection of breast cancer in the health systems of different countries; to evaluate the applicability of the results found in the Brazilian context; and to recommend priority actions in accordance with the implementation strategies of the guidelines to the organizations responsible for these processes in the public health context. A review of systematic reviews was carried out using the supporting policy relevant reviews and trial (SUPPORT) tools to assist in structuring searches and analyzing data. The databases used were PubMed/MEDLINE, Cochrane Library, Virtual Health Library (VHL)/Latin American and Caribbean Health Sciences Literature (Lilacs) and Embase from January 1, 2008 to May 1, 2018. The study of nine selected systematic reviews identified successful actions in developed and developing countries. The strategies identified were: promotion of leadership fronts committed to the implementation of the guidelines, better governance of health services close to the target audience, national mass dissemination campaign and patient navigation program.

KEYWORDS: early detection of cancer; breast neoplasms; public health policy.

\section{RESUMO}

Este projeto de pesquisa teve como objetivo geral identificar estratégias de implementação das diretrizes para a detecção precoce do câncer de mama no Brasil. Em relação aos objetivos específicos, propôs-se a identificar, na literatura especializada, estudos sobre as dificuldades e as estratégias de implementação das diretrizes para a detecção precoce do câncer de mama nos sistemas de saúde de diferentes países; a avaliar a aplicabilidade dos resultados encontrados no contexto brasileiro; e a recomendar ações prioritárias conforme as estratégias de implementação das diretrizes às organizações responsáveis por esses processos no âmbito da saúde pública. Foi realizada uma revisão de revisões sistemáticas utilizando as ferramentas supporting policy relevant reviews and trial (SUPPORT), para auxiliar na estruturação das buscas e na análise de dados. As bases de dados utilizadas foram PubMed/MEDLINE, Cochrane Library, Biblioteca Virtual em Saúde (BVS)/Literatura Latino-Americana e do Caribe em Ciências da Saúde (Lilacs) e Embase de $1^{\circ}$ de janeiro de 2008 a $1^{\circ}$ de maio de 2018. O estudo de nove revisões sistemáticas selecionadas identificou ações exitosas em países desenvolvidos e em desenvolvimento. As estratégias identificadas foram: fomento de lideranças comprometidas com a implementação das diretrizes, melhor governança dos serviços de saúde próximos ao público-alvo, campanha nacional de divulgação em massa e programa de navegação de pacientes.

PALAVRAS-CHAVE: detecção precoce de câncer; neoplasias da mama; políticas públicas de saúde.

${ }^{1}$ Hospital Sírio-Libanês - São Paulo (SP), Brazil.

*Corresponding author: sandra.gioia@gmail.com

Conflict of interests: nothing to declare.

Received on: 06/13/2019. Accepted on: 08/05/2019 


\section{INTRODUCTION}

Breast cancer is generally considered to have a good prognosis when diagnosed and treated early. However, mortality rates for this type of cancer remain high in Brazil, most likely because is still diagnosed in advanced stages. In Brazil, only $20 \%$ of breast cancer cases are diagnosed at an early stage ${ }^{1}$. Women treated in the public health system have unfavorable outcomes compared to women treated in the private system, with worse disease-free and overall survival rates ${ }^{2-5}$.

The main strategies for breast cancer control are: primary prevention (identification and correction of preventable risk factors), secondary prevention (early detection and treatment) and tertiary prevention (rehabilitation and palliative care). Secondary prevention strategies promote a reduction in mortality rates and therefore receive attention from national health systems in general ${ }^{6}$. Mammography is the method of choice for screening standard-risk populations, with no clinical examination or technology being superior to it so far?.

Breast cancer screening programs require well-structured health systems, with assessment of the best cost-effectiveness and the availability of a wide range of management tools. About two decades ago, some developed countries implemented breast cancer screening programs, and nowadays show significant reductions in mortality from breast cancer ${ }^{8}$.

There has been a trajectory of breast cancer prevention and control actions in Brazil since the 1970s. It was during this period that the first initiatives to understand cancer as a major health problem emerged, to be contained by a planned government action'. This trajectory included the implementation of breast cancer control actions, activities, programs and policies and the elaboration of the Guidelines for the Early Detection of Breast Cancer in Brazil in 2015 $5^{10}$.

Identifying possible barriers and the best strategies for the implementation of the guidelines for early detection of breast cancer in Brazil is relevant, as it pushes for improvements in the policy, potentially reducing the magnitude of this issue in the country. Challenges in implementing the guidelines may require changes at several levels, including: changes in the behavior of users and health professionals, organizational changes and changes in the health system. Strategies for achieving these changes are most likely to succeed if they address the barriers to their implementation. However, little is known about the effectiveness or about the different methods of identifying barriers and how to propose interventions to address them ${ }^{11}$.

A structured investigation to identify those barriers can help ensure that none of them are underestimated. This requires a theoretical framework for systematically considering potential barriers and identifying and assessing evidence for the presence of potentially important barriers ${ }^{11}$.

The present study aimed to identify strategies to assist policy makers and those who assist them in implementing the guidelines for early detection of breast cancer in Brazil, focusing on what health systems in other countries that are being more successful in this policy - with better indicators - are adopting. To assist in the structuring of the data search and analysis, the SUPPORT tools were used, which were designed for evidence-informed policymaking (EIPM) based on the best available scientific evidence ${ }^{12}$.

\section{METHODOLOGY}

This study carried out a review of systematic reviews, a type of study designed to provide a synthesis and integrate information from various studies in order to reduce uncertainty in decision-making and ensure that this process is supported by the best scientific evidence available ${ }^{13}$. For the development of this study, the SUPPORT toolset was adopted, which provides the basis for the elaboration of policies informed by scientific evidence ${ }^{11}$.

In the first stage, the issue to be addressed was characterized and structured to motivate the detailing of its confrontation. In the second stage, effective strategies were identified to deal with the issue through structured search in the following indexed bases:

- PubMed/MEDLINE;

- Cochrane Library;

- Virtual Health Library (BVS)/Latin American \& Caribbean Health Sciences Literature (Lilacs);

- Embase.

Regarding the search, the period was restricted from January 1, 2008 to May 1, 2018, because an extended period did not add to the number of publications of interest. Inclusion criteria were: year and period of publication; availability of the full systematic review article in English, Portuguese, French or Spanish; and use of descriptors. The search filter for systematic reviews used - with adaptations depending on the source - is detailed in Chart 1.

All articles found were randomly organized for analysis based on their abstracts. The information was arranged in a data extraction table. The main study question was: what are the barriers to overcome strategies for implementing early breast cancer detection guidelines in developed and developing countries? The articles were selected according to the PICO format, with P (problem) being the barriers to the implementation of early detection guidelines, I (intervention) being the strategies to overcome barriers, $\mathrm{C}$ (comparison) being the different strategies used in developing countries and $\mathrm{O}$ (outcome) being greater adherence to the guidelines.

After reading the selected texts, duplicate studies and those that did not meet the interest criteria were excluded, that is, those that did not explore the strategies to overcome barriers (Figure 1). Selection criteria were applied to the full text of potentially eligible 
reviews, and the reliability of reviews that met all other selection criteria was assessed, as shown in Chart 2.

Fields used for data extraction in the studies were: lead author, year of publication, place of study, study reliability, objective(s), results, barriers, and implementation strategies. Details of the included articles can be found in Chart 3.

Examples of how the different implementation strategies worked in the locations studied, considering the different determinants of organizational change in the system, practitioners' practice, and users' use of health services ${ }^{11}$, are shown in Chart 4. These actions, ultimately, aimed at increasing mammographic coverage rate and quality of services, optimizing time for diagnosis and treatment, and reducing morbidity and mortality.

\section{DISCUSSION}

These nine reviews summarize the evidence base that supports strategies for implementing guidelines aimed at early detection of breast cancer globally. Each location selected strategies considering the existing barriers, resources and health structure ${ }^{15}$.

The studies presented strategies for implementing early detection guidelines in the most vulnerable populations, such as low-income, low-educated individuals in developed countries, Latinos, Asians, Native Americans, Alaskan natives, African Americans. Patients in low- and middle-income countries face structural barriers that are similar to those faced by deprived patients in developed countries ${ }^{14-22}$.

Chart 1. Filtro de buscas para revisões sistemáticas usadas.

PubMed/MEDLINE

((Health Plan Implementation[mh] OR "Health Plan Implementation"[tiab] OR "barriers to implementation"[tiab] OR "implementation strategies"[tiab] OR health policy[mh] OR health polic*[tiab] OR guidelines as topic[mh] OR guideline*[tiab] OR barriers[tiab])) AND ((Early Detection of Cancer[mh] OR "early detection"[tiab] OR early diagnosi*[tiab]) AND ((Breast Neoplasms[mh] OR breast[tiab]) AND (neoplasm*[tiab] OR cancer*[tiab] OR tumour*[tiab] OR tumour*[tiab] OR onco*[tiab] OR carcinoma*[tiab])))) AND (Review[ptyp] AND "2008/05/07"[PDat]: "2018/05/04"[PDat] AND "humans"[MeSH Terms] AND (English[lang] OR French[lang] OR Portuguese[lang] OR Spanish[lang]))

\section{Cochrane Library}

(([mh "Health Plan Implementation"] or "Health Plan Implementation":ti,ab or "barriers to implementation":ti,ab or "implementation strategies":ti,ab or [mh "health policy"] or health polic*:ti,ab or [mh "guidelines as topic"] or guideline*:ti,ab or barriers:ti,ab) and (([mh "Early Detection of Cancer"] or "early detection":ti,ab or early diagnosi*:ti,ab) and (([mh "Breast Neoplasms"] or breast:ti,ab) and (neoplasm*:ti,ab OR cancer*:ti,ab OR tumour*:ti,ab or tumour*:ti,ab or onco*:ti,ab or carcinoma*:ti,ab))))

\section{BVS/LILACS}

(tw:("Health Planlmplementation" OR "implementação de planos de saúde" OR "implementación de planes de salud" OR "barrierstoimplementation" OR "barreiras para implementação" OR "barreras para laimplementación" OR "implementationstrategies" OR "estratégias de implementação" OR "estrategias de implementación" OR "healthpolicy" OR "políticas de saúde" OR "políticas de salud" OR guidelines OR guias OR barriers OR barreiras OR barreras)) AND (tw:("earlydetection" OR "earlydiagnosis" OR "detecção precoce" OR "deteccionprecoz" OR "diagnóstico precoce" OR "diagnostico precoz")) AND (tw:("BreastNeoplasms" OR breast* OR "neoplasias da mama" OR "cancer de mama" OR mama)) AND (tw:(neoplas* OR cancer* OR tumour* OR tumour* OR onco* OR carcinoma*)) AND (instance:"regional”) AND ( db:("LILACS") AND year_cluster:("2011" OR “2009" OR “2013" OR "2012" OR "2016" OR "2010" OR "2015" OR "2014" OR "2008")

\section{Embase}

('health care planning'/exp OR 'community health planning':ti,ab OR 'health and welfare planning':ti,ab OR 'health care planning':ti,ab OR 'health plan implementation':ti,ab OR 'health planning':ti,ab OR 'health planning councils':ti,ab OR 'health planning database':ti,ab OR 'health planning guidelines':ti,ab OR 'health planning organisations':ti,ab OR 'health planning organizations':ti, ab OR 'health planning support':ti,ab OR 'health planning technical assistance':ti,ab OR 'health priorities':ti,ab OR 'health resources':ti,ab OR 'health systems plans':ti,ab OR 'healthcare planning':ti,ab OR 'medically underserved area':ti,ab OR 'national health planning information center':ti, ab OR 'national health planning information center (u.s.)':ti,ab OR 'regional health planning':ti,ab OR 'regional medical programmes':ti,ab OR 'regional medical programs':ti,ab OR 'state health planning and development agencies':ti,ab OR 'state health plans':ti,ab OR 'strategic stockpile':ti,ab OR 'underserved neighborhood':ti,ab OR 'barriers to implementation':ti,ab OR 'implementation strategies':ti,ab OR 'health care policy'/exp OR 'health care policy':ti,ab OR 'health care reform':ti,ab OR 'health policy':ti,ab OR 'healthcare policy':ti,ab OR 'healthcare reform':ti,ab OR 'patient protection and affordable care act':ti,ab OR 'policy, health care':ti,ab OR 'practice guideline'/ $\exp$ OR 'clinical practice guidelines':ti,ab OR 'guidelines':ti,ab OR 'guidelines as topic':ti,ab OR 'practice guideline':ti,ab OR 'practice guidelines':ti,ab OR 'practice guidelines as topic':ti,ab) AND ('early cancer diagnosis'/exp OR 'early cancer diagnosis':ti,ab OR 'early detection of cancer':ti, ab OR 'early diagnosis'/exp OR 'diagnosis, early':ti,ab OR 'early diagnosis':ti, ab) AND ('breast tumor'/exp OR 'breast gland tumor':ti,ab OR 'breast gland tumour':ti,ab OR 'breast mass':ti,ab OR 'breast neoplasms':ti,ab OR 'breast neoplasms, male':ti,ab OR 'breast tumor':ti,ab OR 'breast tumour':ti,ab OR 'female breast neoplasm':ti,ab OR 'female breast tumor':ti,ab OR 'female breast tumour':ti,ab OR 'mamma tumor':ti,ab OR 'mamma tumour':ti,ab OR 'mammary gland tumor':ti,ab OR 'mammary gland tumour':ti,ab OR 'mammary neoplasms':ti,ab OR 'mammary tumor':ti,ab OR 'mammary tumor cell':ti,ab OR 'mammary tumour':ti,ab OR 'mammary tumour cell':ti,ab OR 'unilateral breast neoplasms':ti,ab) AND [embase]/lim NOT ([embase]/lim AND [medline]/lim) AND (2008:py OR 2009:py OR 2010:py OR 2011:py OR 2012:py OR 2013:py OR 2014:py OR 2015:py OR 2016:py OR 2017:py OR 2018:py)

VHL: Virtual Health Library; Lilacs: Latin American and Caribbean Health Sciences Literature. 
In peripheral countries, deprived urban populations, remote populations or indigenous people often cannot receive cancer care in a timely manner due to lack of awareness, fragmented and complex health systems, low socioeconomic status, cultural barriers and limited financial and human resources in public health institutions ${ }^{8}$. This helps in the applicability of the strategies identified in the study in the Brazilian scenario, prone to low adherence to early detection recommendations due to socioeconomic and cultural factors ${ }^{23}$.

Limitations in applying the guideline implementation strategies in low- and middle-income countries may be related to issues such as scarcity or poor distribution of health professionals and insufficient availability of medical products and supplies, which are clearly not limited to the provision of breast health related services. Similarly, the issues associated with access to services and the ability (or inability) to finance them transcend the issues of this review due to being truly systemic ${ }^{24}$.

\section{Health organizations}

Strategies for implementing guidelines at the health organization level have the following determinants: inadequate internal communication, inadequate processes and inadequate leadership. Examples of actions to reduce structural barriers and direct costs to patients and to involve leaders and experts in breast cancer in primary care educational activities were explored $\mathrm{d}^{15-17,20-22}$.

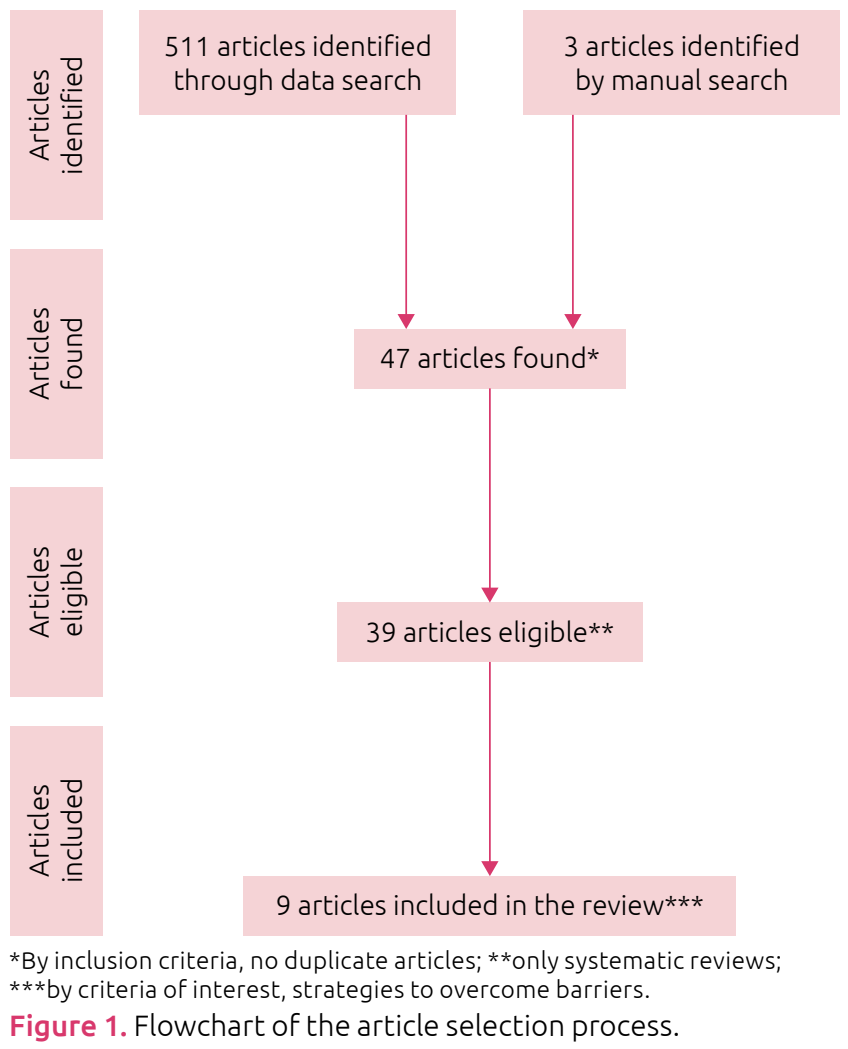

The studies ${ }^{15-17,20-22}$ evaluated interventions to facilitate the delivery of care services to the population. Interventions to reduce structural barriers and costs to the patient were addressed. Structural barriers are non-economic barriers that prevent access to guideline recommendations. Interventions to lower these barriers were explored, providing: services close to the target population; alternative service hours; mobile mammographs; convenient service locations such as schools, clubs, and churches; home visit; female health professionals; text messages to remember appointments, diagnostic and follow-up exams, and patient navigator.

Using a patient navigator facilitates the proper and efficient use of services. It is considered an indicator of quality in many health services in the United States, Canada and Europe and is still poorly studied in peripheral countries. The navigator is a health worker trained to be a case manager and serves as a link between patients and the system, health professionals and providers, bringing equity to vulnerable populations ${ }^{24,25}$.

Bowser et al. ${ }^{16}$ reported greater adherence to the guidelines when female health professionals were involved in clinical care and imaging. This gender-related barrier for health professionals was very relevant for assessing the applicability of interventions in the Middle East and North Africa region.

Lu et al. ${ }^{17}$ identified studies proving the effectiveness of home visits by health professionals in countries such as Thailand, New Zealand, India, Pakistan, Bangladesh and Singapore. Women receive health education and letters or reminders to undergo screening. This approach increases adherence to other health care procedures, such as colpocytology and control of systemic arterial hypertension, diabetes mellitus and dyslipidemia.

The use of mobile mammographs aims to supply places with repressed demand and with a long wait for mammography, as well as to stimulate the screening and early diagnosis of breast cancer. There are several factors that can lead women to not get screened, including lack of time, fear of pain and embarrassment during the exam and, in some cases, the distance to go to a mammography service. Hence the importance of a continuous screening program combined with mobile mammographs ${ }^{14,17,18,20}$.

Baron et al. ${ }^{15}$ evaluated studies that addressed reducing costs to patients as an effective action to promote adherence to guidelines in the United States, such as performing regular screening mammograms by the target population or mammograms for diagnosis. The use of vouchers, reduced co-participation, reimbursements and state insurance coverage were exemplified.

Sabatino et al..$^{19}$ conducted an update of systematic reviews that recommend the engagement of active leadership and breast cancer specialists working in educational groups with patients and primary care health professionals. Interactive education programs addressing the advantages of adhering to the guidelines promote continuous improvement in the quality of breast health processes. 
Chart 2. SUPporting POlicy relevant Reviews and Trials (SUPPORT) Summary Checklist for judgment about how much confidence to place in a systematic review.

Study:

Date:

Section A: Methods used to identify, include and critically evaluate studies

A.1 Were the criteria used to decide studies included in the reported review?

The authors specified:

- Types of Studies

- Participants/contexts/population

- Intervention(s)

- Result(s)

Coding guide - check the answers above:

YES: All four should be yes.

Comments (please note important limitations or uncertainties)

A. 2 Was the search for evidence reasonably comprehensive?

The following was ensured:

- Language bias avoided (no language-based inclusion restriction)

- No inclusion restriction based on publish status

Relevant databases searched (including PubMed/MEDLINE + Cochrane Library)

- Reference lists verified in the articles included

- Contacted Authors/Experts

Coding guide - check the answers above:

YES: All five should be yes.

PARTIALLY: The relevant databases and reference lists are both checked.

Comments (please note important limitations or uncertainties)

A. 3 Is the review reasonably up to date?

Have the researches been conducted recently enough that it is unlikely to find newer researches or to alter the results of the review?

Coding guide: Consider how many years have passed since the last research (for example,

if it was more than 10 years ago, the review is unlikely to be up to date) and if there are any ongoing researches

Comments (please note important limitations or uncertainties)

A.4 Was there bias in the selection of articles avoided?

The authors specified:

- Explicit selection criteria

- Independent full-text screening by at least two reviewers

- List of included studies provided

- List of excluded studies provided

Coding guide - check the above:

YES: All four should be yes.

Comments (please note important limitations or uncertainties)

A.5 Did the authors use appropriate criteria to assess the risk of bias in the analysis of the included studies?

- The criteria used to assess the risk of bias have been reported

- A table or summary of the evaluation of each study included for each criterion was reported - Sensitive criteria focusing on risk of bias (not other study qualities such as accuracy or applicability) were used

Coding guide - check the above:

Yes

Partially

No

YES: All three should be yes.

Comments (please note important limitations or uncertainties)

A.6 General - How should you use the methods used to identify, include and critically evaluate studies?

The summarized assessment score A relates to the five questions above.

If "No" or "Partially" is used for any of the above questions, the review is likely to have important limitations. Examples of important limitations may include not reporting explicit selection criteria and not providing a criterion for including studies or assessing the risk of bias in the included studies.

Comments (please note important limitations or uncertainties)
- Major limitations (limitations that are important enough that the review results are unreliable and should not be used in the policy summary)

- Important limitations (limitations important enough to search for another systematic review and to interpret the results of that review with caution if another review cannot be found) - Reliable (minor limitations only) 
Chart 2. Continuation.

Section B: Methods used to analyze findings

B.1 What are the characteristics and results of included studies reported as reliable?

- Been there: Independent data extraction by at least two reviewers

- A table or summary of participant characteristics, interventions and outcomes for included studies

- A table or summary of the results of the included studies.

Coding guide - check the above:

YES: All three should be yes.

Comments (please note important limitations or uncertainties)

B.2 Regarding the methods used by reviewers to analyze the results of the included studies, were they reported?

\begin{tabular}{l|c} 
Yes & $\begin{array}{c}\text { Partially } \\
\text { No }\end{array}$ \\
Comments (please note important limitations or uncertainties) & Not applicable (e.g., no studies included)
\end{tabular}

B.3 Did the review describe the extent of heterogeneity?

- Did the review ensure that the included studies were similar enough to make sense to combine them, to split the included studies sensibly into homogeneous groups, or to reasonably conclude that it did not make sense to combine or group the included studies? - Did the review discuss to what extent there were significant differences in the results of the included studies?

- If a meta-analysis was performed, were the $\mathrm{l}^{2}$, the $\mathrm{x}^{2}$ test for heterogeneity, or other appropriate statistics reported?

Comments (please note important limitations or uncertainties)

\section{Yes \\ Partially \\ No}

Not applicable (e.g., no studies included)

B.4 Have the results of relevant studies been combined (or not combined) appropriately in relation to the primary issue that the review addresses and the available data?

How was data analysis carried out?

- Descriptive, only

- Vote count based on effect direction

- Vote count based on statistical significance

- Description of effect size range

- Meta-analysis

- Meta-regression

- Other: Specify

- Not applicable (e.g.: no studies or no data)

How were the studies weighted in the analysis?

- Equal weights (this is done when vote count is used)

- By quality design or study (this is rarely done)

- Inverse variance (this is done in the anamnesis analysis)

- Number of participants

- Other: Specify

- Not clear

- Not applicable (e.g.: no studies or no data)

Did the review address the errors in the analysis unit?

- Yes, it took into account the grouping (for example, intracluster correlation coefficient used)

- No, but the issue of errors in the analysis unit has been recognized

- No mention of the problem

- Not applicable - no clustered studies or studies included

- Coding guide - check the above:

If narrative OR vote counting (where quantitative analysis would have been possible) OR inadequate table, graph or meta-analysis OR analysis unit error not addressed (and should have been), the likely answer is NO.

If considered appropriate and the graphic analysis, the appropriate weights and the extent of heterogeneity were taken into account, the likely answer is YES.

If there are no studies/no data: NOT APPLICABLE

If you are unsure: CAN'T SAY/PARTIALLY

Comments (please note important limitations or uncertainties)

\section{Yes \\ Partially \\ No}

Not applicable (e.g., no studies included) 
Chart 2. Continuation.

\begin{tabular}{|l|c|}
\hline B.5 Does the analysis examine the extent to which specific agents can explain the differences between included studies? \\
\hline - The factors pointed out by the authors should be considered as explanatory factors & Yes \\
described clearly? & Can't say/Partially \\
- Was a sensible method used to explore the extent to which key factors explained & No Not applicable (e.g.: few studies with no \\
heterogeneity? & major differences in the results of the \\
- Descriptive/textual & included studies or the included studies \\
- Meta-regression & were so different that it would make \\
- Graphic & sense to explore the heterogeneity of \\
- Others & the results) \\
Comments (please note important limitations or uncertainties) & \\
\hline B.6 Overall, how would you rate the methods used to analyze findings related to the primary issue addressed in the review?
\end{tabular}

B.6 Overall, how would you rate the methods used to analyze findings related to the primary issue addressed in the review?

A pontuação da avaliação resumida B relaciona-se com as cinco perguntas desta seção, referentes à análise. Se a opção "Não" ou "Parcialmente" for usada para qualquer uma das cinco perguntas anteriores, a revisão provavelmente terá limitações importantes. Exemplos de grandes limitações podem incluir não relatar características críticas dos estudos incluídos ou não relatar os resultados dos estudos incluídos.

Use comentários para especificar se é relevante, para marcar a incerteza ou necessidade de discussão

Section C: Review reliability overall assessment

C.1 Are there any other aspects of the review not mentioned before that leads you to question the results?
- Major limitations (limitations that are important enough that the review results are unreliable and should not be used in the policy summary)

- Important limitations (limitations important enough to search for another systematic review and to interpret the results of that review with caution if another review cannot be found)

- Reliable (minor limitations only)

- Additional Methodological Issues

- Interpretation

- Robustness

- Conflicts of interest (from review authors or included studies) - Other

- No other quality issues identified

C.2 Based on the assessments of the above methods, how would you rate the reliability of the review?

- Major limitations (exclude); briefly (and politely) state the reasons for excluding the review by completing the following sentence: This review has not been included in this policy summary for the following reasons: Comments (briefly summarize any key messages or useful information that may be extracted from the review for analysis by policy makers or managers):

- Important limitations; briefly (and politely) state the most important limitations by editing the following sentence, if necessary, and specifying the important limitations: This review has important limitations.

- Reliable; carefully note any comments that should be noted regarding the reliability of this review by editing the following sentence if necessary: This is a systematic review of good quality, with only minor limitations.

\section{Health professionals}

Actions to increase adherence by health professionals to early detection guidelines revolve around the following pillars: knowledge, competence, attitudes and motivation to change. Professionals performing the first care procedures on women are not always able to detect and manage cases of breast disease and/or to be aware of guidelines ${ }^{23}$.

The following are recommended for the training of health professionals: dissemination of educational materials; educational activities or visits to reference units for breast cancer diagnosis and treatment; dissemination of information about the severity of the problem, including relevant comparisons; presence of expert leaders; dissemination of information aimed to motivate health professionals to change their practices; financial or other incentives; reducing the burden of the changes in practices ${ }^{16,17,19,21}$.
Peterson et al. ${ }^{18}$ studied systematic reviews that assessed the impact of communication between health professionals and patients on adherence to early detection of breast cancer. In general, the results suggested that professional recommendation was necessary but not sufficient for optimal adherence to early detection guidelines. Studies that examined the quality of communication indicated that information and shared decision-making were more closely related to behavior favoring recommendations. Training professionals on communication is an effective tool for improving adherence to recommendations.

The training of primary care health professionals, as a tool to improve patient flow to the breast health care line, should be supported by managers and involve breast cancer specialists ${ }^{26}$. The study conducted by researchers at Imperial College London, in collaboration with the Ministry of Health's Oswaldo Cruz Foundation's Center for Health Knowledge and Data Integration 


\begin{tabular}{|c|c|c|c|c|}
\hline $\begin{array}{l}\underline{y} \\
\overrightarrow{\vec{y}} \\
\stackrel{y}{x}\end{array}$ & 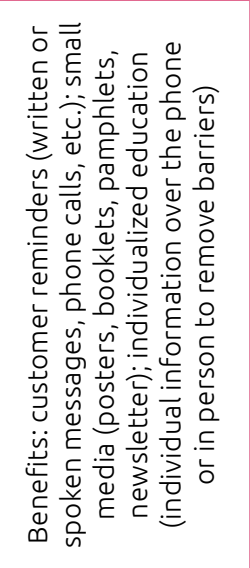 & 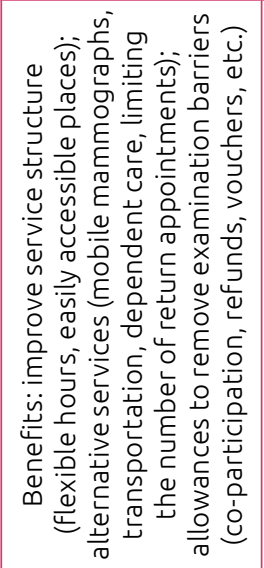 & 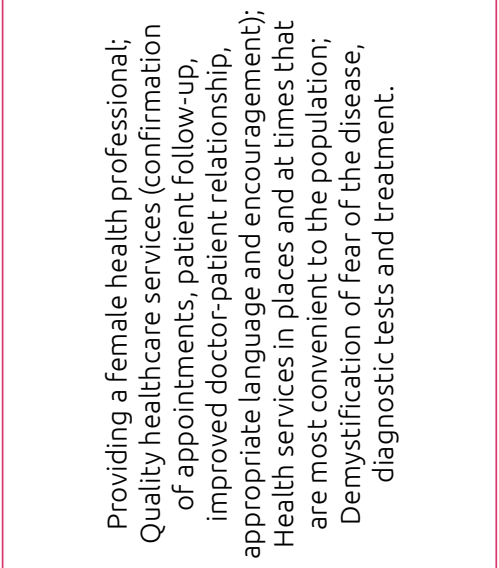 & 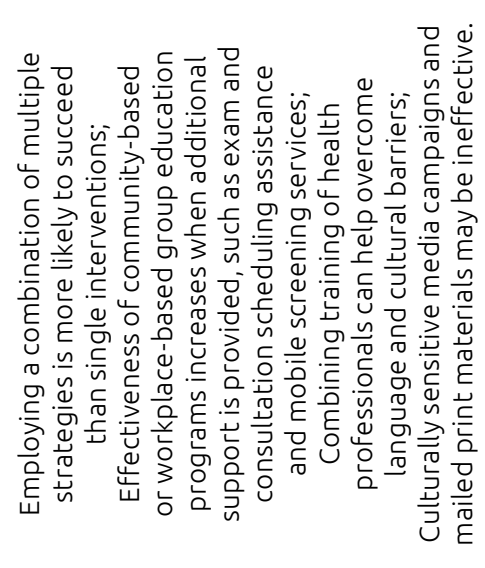 \\
\hline 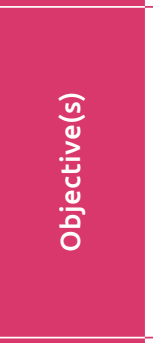 & 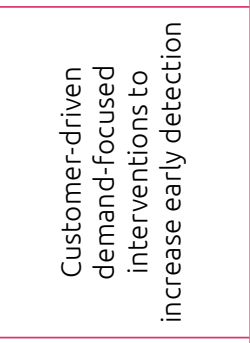 & 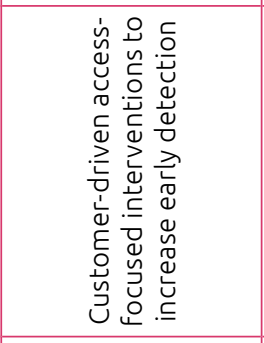 & 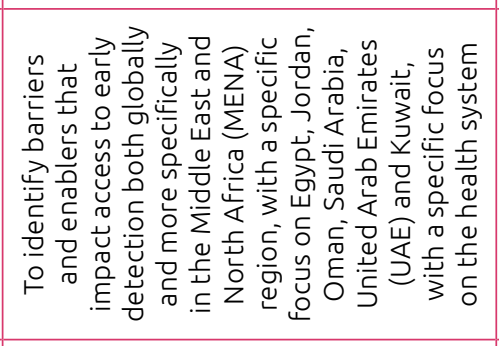 & 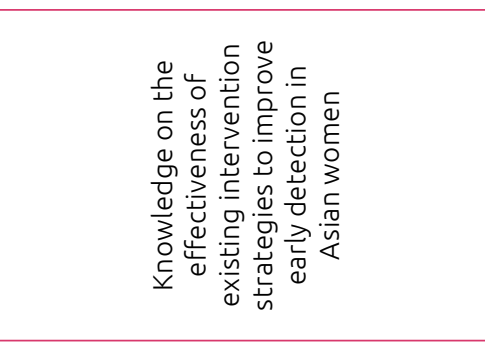 \\
\hline 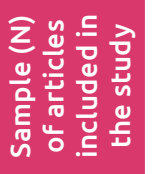 & $\stackrel{\stackrel{\Xi}{\simeq}}{ }$ & $\stackrel{\sim}{\sim}$ & 㶽 & 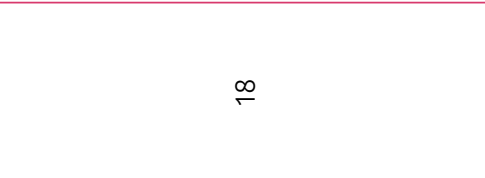 \\
\hline 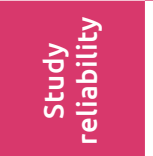 & $\begin{array}{l}\frac{0}{0} \\
\frac{0}{\overline{0}} \\
\frac{0}{0}\end{array}$ & $\begin{array}{l}\frac{0}{0} \\
\frac{.0}{\bar{Q}} \\
\simeq\end{array}$ & $\begin{array}{l}\frac{\otimes}{0} \\
\frac{.0}{\bar{Q}} \\
\simeq\end{array}$ & 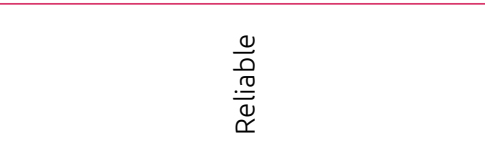 \\
\hline 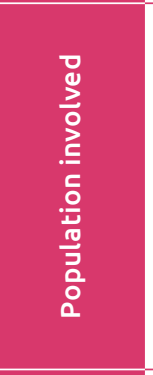 & 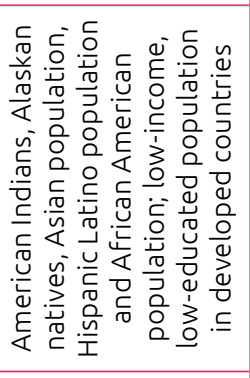 & 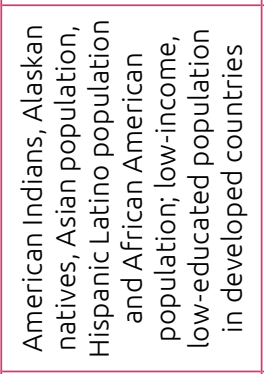 & 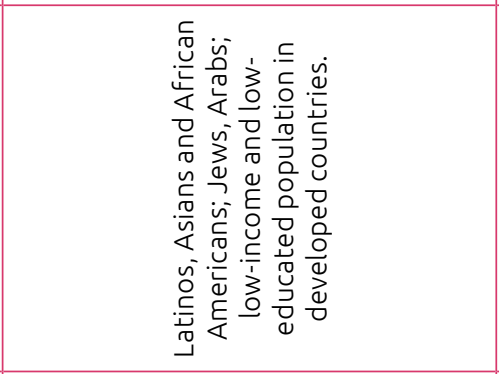 & $\begin{array}{l}\tilde{n} \\
\frac{0}{n} \\
\frac{0}{4}\end{array}$ \\
\hline 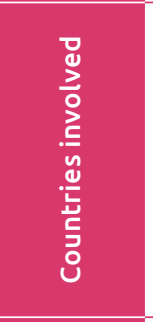 & 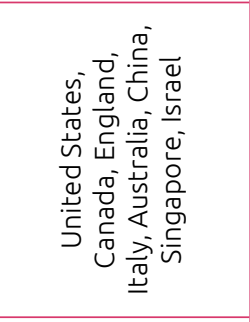 & 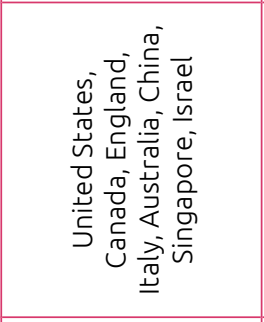 & 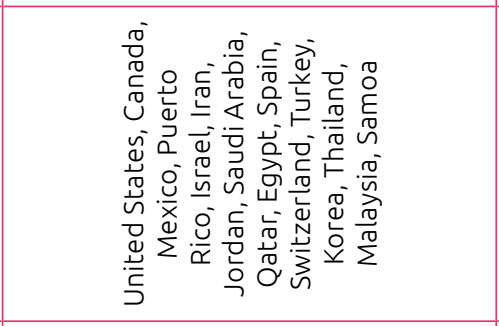 & 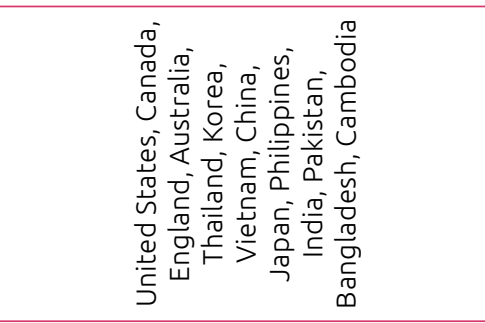 \\
\hline 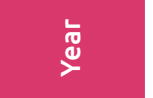 & $\stackrel{\infty}{\stackrel{\sim}{े}}$ & $\stackrel{\infty}{\stackrel{\sim}{\sim}}$ & $\stackrel{\grave{\sim}}{\sim}$ & $\stackrel{\sim}{\stackrel{\sim}{\sim}}$ \\
\hline 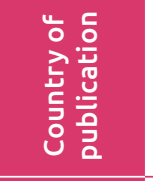 & 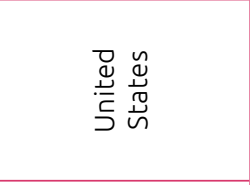 & 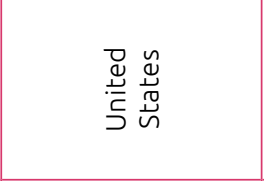 & 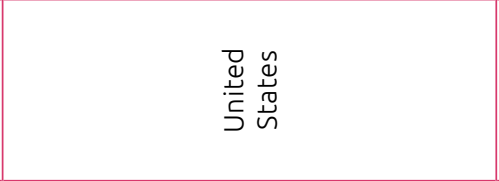 & $\begin{array}{l}0 \\
0 \\
0 \\
0 \\
0 \\
0\end{array}$ \\
\hline 동 & 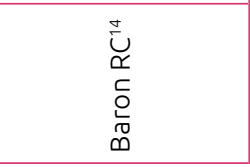 & 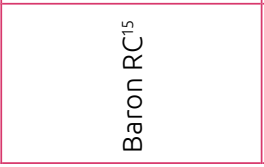 & 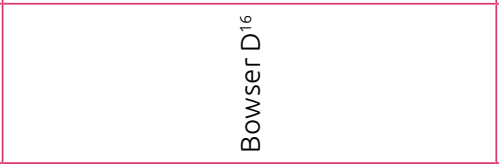 & $\sum_{J}^{N}$ \\
\hline
\end{tabular}




\begin{tabular}{|c|c|c|c|c|c|}
\hline $\begin{array}{l}\underline{y} \\
\overrightarrow{\vec{y}} \\
\underline{y}\end{array}$ & 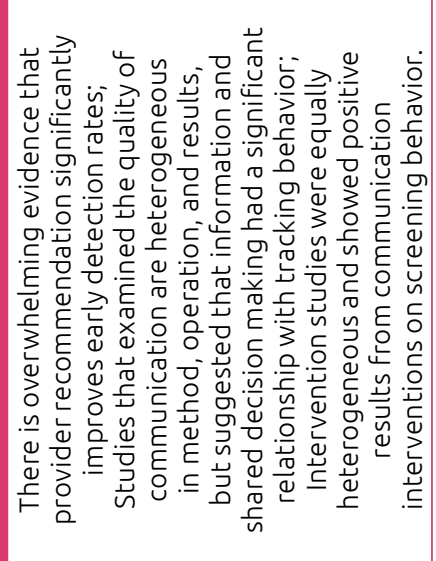 & 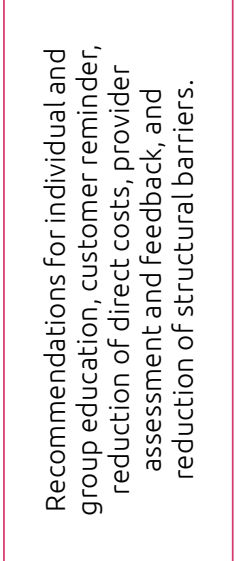 & 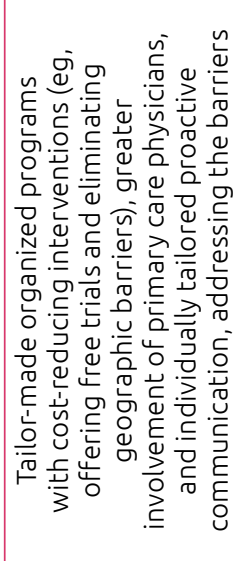 & 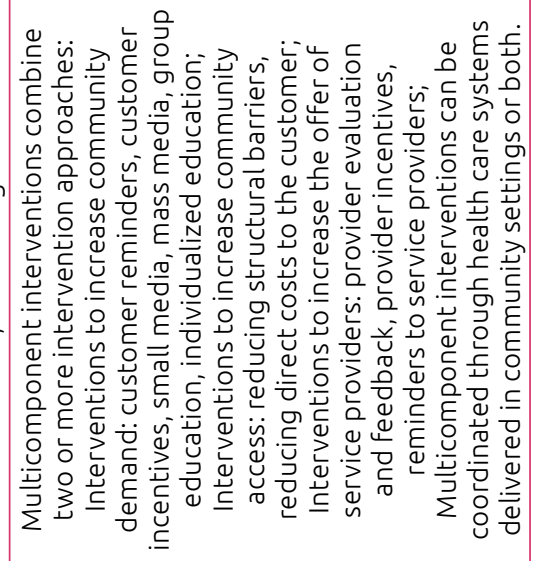 & 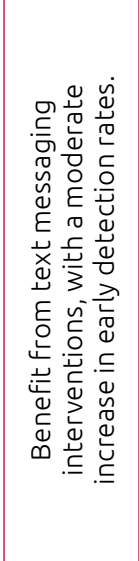 \\
\hline 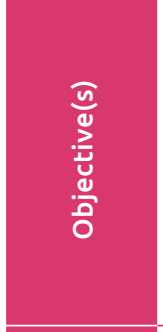 & 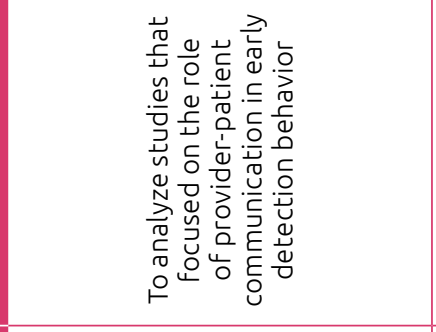 & 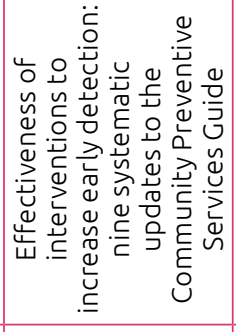 & 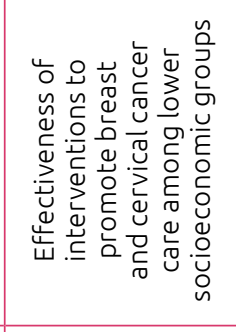 & 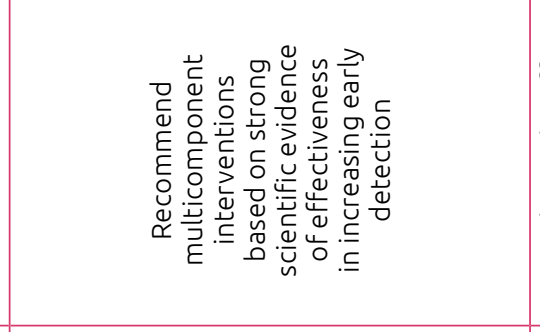 & 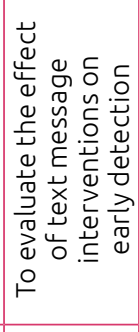 \\
\hline 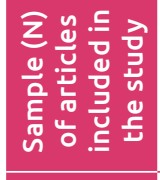 & $\stackrel{\stackrel{n}{m}}{n^{\prime}}$ & $\stackrel{\leftrightarrow}{\sigma}$ & $\stackrel{\sim}{ }$ & $\begin{array}{l}\infty \\
\infty\end{array}$ & $\sigma$ \\
\hline 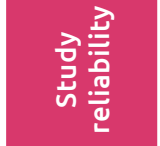 & $\begin{array}{l}\frac{0}{0} \\
\frac{0}{\overline{0}} \\
\simeq \\
\simeq\end{array}$ & $\begin{array}{l}\frac{0}{0} \\
\frac{0}{0} \\
\simeq\end{array}$ & 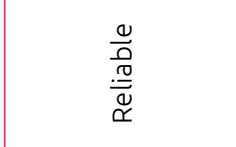 & $\begin{array}{l}\frac{0}{0} \\
\frac{.0}{0} \\
\simeq\end{array}$ & $\begin{array}{l}\frac{0}{0} \\
\frac{.0}{\overline{0}} \\
\simeq\end{array}$ \\
\hline 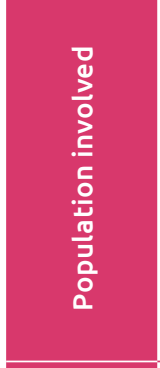 & 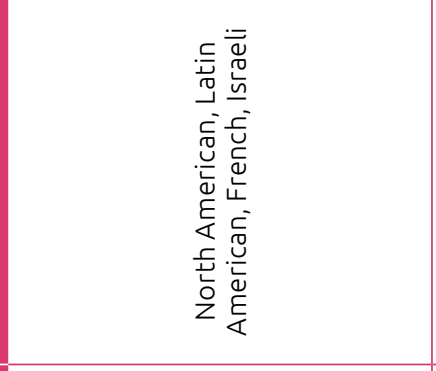 & 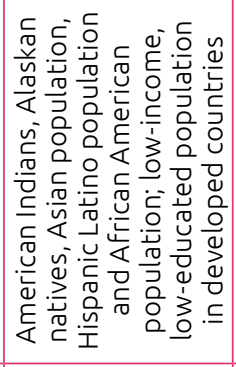 & 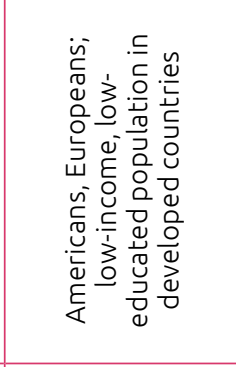 & 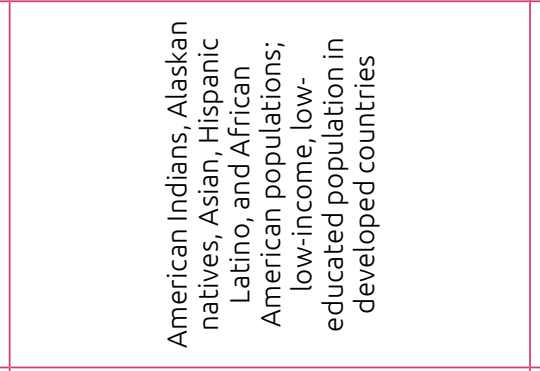 & 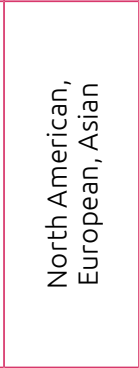 \\
\hline 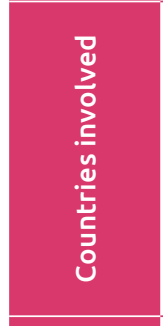 & 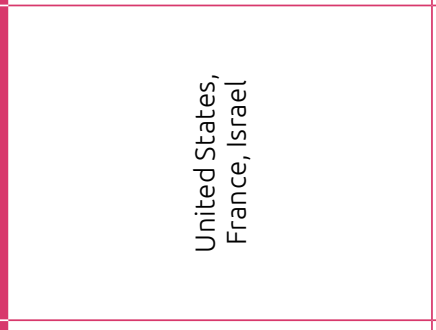 & 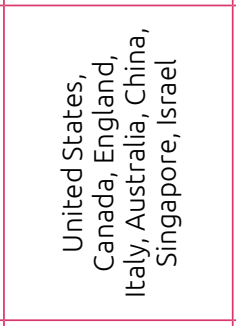 & 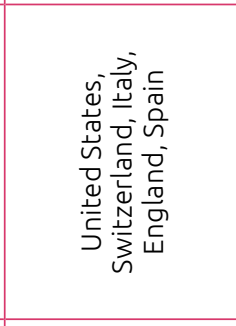 & 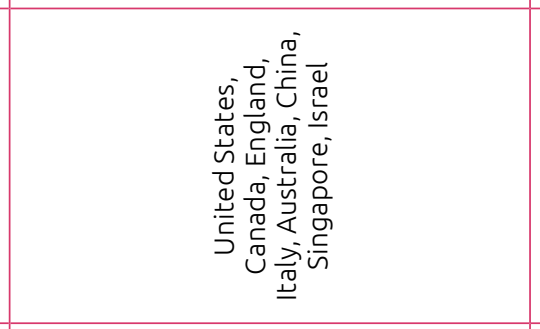 & 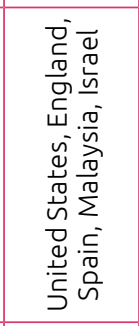 \\
\hline 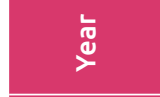 & $\stackrel{\circ}{\stackrel{N}{N}}$ & $\stackrel{\sim}{\sim}$ & $\stackrel{\circ}{\stackrel{2}{\nu}}$ & $\stackrel{\circ}{\stackrel{N}{N}}$ & 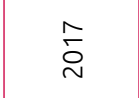 \\
\hline 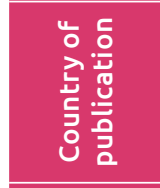 & 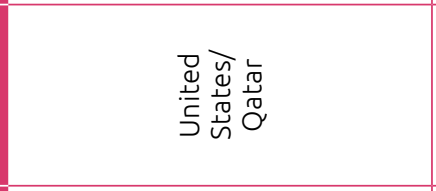 & 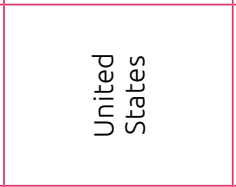 & 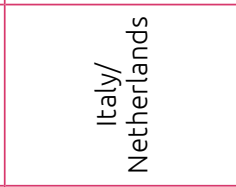 & 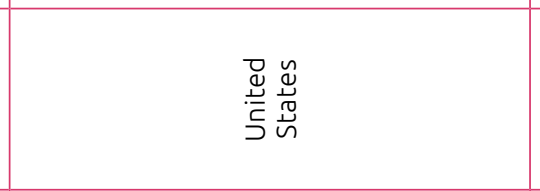 & 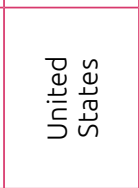 \\
\hline 我 & 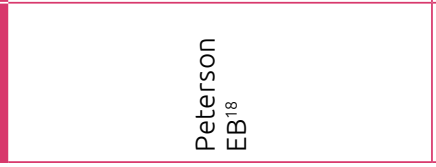 & 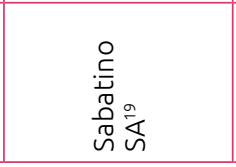 & 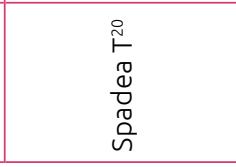 & 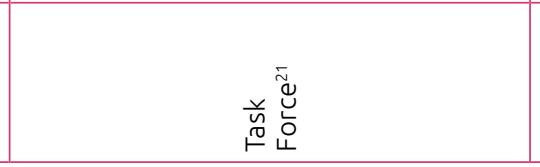 & 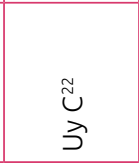 \\
\hline
\end{tabular}


(Fiocruz), found that the highest level of governance and increased health coverage in primary care in Brazilian municipalities are associated with reduced mortality ${ }^{26}$. The family health strategy can be a good context for initiating organized breast cancer screening in Brazil, contributing to the strengthening of the guidelines.

\section{Healthcare Users}

There are multiple barriers for users to get breast cancer care. The nine studies addressed these barriers and strategies for implementing early detection guidelines ${ }^{14-22}$. Prioritized actions are based on the following determinants: knowledge, competence, attitudes, access to care and motivation to change. Users may not recognize the effectiveness of the guidelines or agree with the recommendations for fear of the disease or lack of awareness of breast cancer issues. Economic, social, cultural or religious barriers make it difficult to change user behavior and seek effective care for early detection ${ }^{14-22}$.

Reliable and accessible information on the problem should be sought, for example, using mass media, small media (leaflets, posters, newsletters) and community health professionals; reduce financial or physical barriers to care by using appointment and exam reminders, flexible appointment and exam times, mobile

Chart 4. Strategies for implementing early breast cancer detection guidelines.

\begin{tabular}{|c|c|c|c|}
\hline Level & & Determinants & Actions \\
\hline \multirow[t]{3}{*}{$\begin{array}{l}\text { Health } \\
\text { organizations }\end{array}$} & $\begin{array}{l}\text { Inadequate } \\
\text { internal } \\
\text { communication }\end{array}$ & $\begin{array}{l}\text { The necessary communication } \\
\text { between different levels of the } \\
\text { health system may be lacking. }\end{array}$ & $\begin{array}{l}\text { Structured reference sheets; involvement } \\
\text { of breast cancer specialists in primary care } \\
\text { education activities; patient navigator use. }\end{array}$ \\
\hline & $\begin{array}{l}\text { Inadequate } \\
\text { processes }\end{array}$ & $\begin{array}{l}\text { Patient referral and counter-referral } \\
\text { processes may not be appropriate for } \\
\text { the implementation of the guidelines. }\end{array}$ & $\begin{array}{l}\text { Process redesign to facilitate appropriate and } \\
\text { efficient use of services (continuous quality } \\
\text { improvement); patient navigator use. }\end{array}$ \\
\hline & $\begin{array}{l}\text { Inadequate } \\
\text { leadership }\end{array}$ & $\begin{array}{l}\text { There may be insufficient leadership } \\
\text { to implement the guidelines. }\end{array}$ & $\begin{array}{l}\text { Identification of effective leaders; expert } \\
\text { engagement; establishment of leadership systems. }\end{array}$ \\
\hline \multirow[t]{4}{*}{$\begin{array}{l}\text { Health } \\
\text { professionals }\end{array}$} & Knowledge & $\begin{array}{l}\text { Healthcare professionals may not } \\
\text { be aware of the likely impacts of } \\
\text { early detection guidelines. }\end{array}$ & Dissemination of educational materials. \\
\hline & Competence & $\begin{array}{l}\text { Healthcare professionals may not feel } \\
\text { competent or may not have competence. }\end{array}$ & $\begin{array}{l}\text { Educational activities or visits to reference units for } \\
\text { the diagnosis and treatment of breast cancer. }\end{array}$ \\
\hline & Attitudes & $\begin{array}{l}\text { Health professionals may not } \\
\text { agree that the implementation } \\
\text { of the guidelines is effective. }\end{array}$ & $\begin{array}{l}\text { Disclosure of information about the severity of the } \\
\text { problem, including relevant comparisons; presence } \\
\text { of opinion leaders and breast cancer experts. }\end{array}$ \\
\hline & $\begin{array}{l}\text { Motivation } \\
\text { to change }\end{array}$ & $\begin{array}{l}\text { Health workers cannot be motivated } \\
\text { to change their practices. }\end{array}$ & $\begin{array}{l}\text { Dissemination of information designed to } \\
\text { motivate healthcare professionals to change their } \\
\text { practices; financial or other types of incentives; } \\
\text { reducing the burden of changing practices. }\end{array}$ \\
\hline \multirow[t]{5}{*}{ Health users } & Knowledge & $\begin{array}{l}\text { People may not be aware of the likely } \\
\text { impacts of the early detection guidelines. }\end{array}$ & $\begin{array}{l}\text { Dissemination of reliable and accessible } \\
\text { information, for example using mass media, } \\
\text { small media (flyers, posters, newsletters), } \\
\text { community health workers, patient navigator. }\end{array}$ \\
\hline & Competence & $\begin{array}{l}\text { People may not recognize the } \\
\text { effectiveness of the guidelines. }\end{array}$ & Provision of training and support; patient navigator use. \\
\hline & Attitudes & $\begin{array}{l}\text { People may not agree that implementing } \\
\text { the guidelines is important due to fear } \\
\text { of the disease or lack of awareness } \\
\text { of the issue of breast cancer. }\end{array}$ & $\begin{array}{l}\text { Disclosure of information about the } \\
\text { severity of the problem, including relevant } \\
\text { comparisons; patient navigator use. }\end{array}$ \\
\hline & Access to care & $\begin{array}{l}\text { People may not have access to the } \\
\text { types of operations that are effective } \\
\text { for early detection due to financial, } \\
\text { social, cultural or religious constraints. }\end{array}$ & $\begin{array}{l}\text { Reduction of financial or physical barriers to } \\
\text { care; appointment and exam reminders; mobile } \\
\text { mammographs; female health professionals; patient } \\
\text { follow-up; better doctor-patient relationship, with } \\
\text { proper language and encouragement; demystification } \\
\text { of fear of the disease, the diagnostic tests and the } \\
\text { treatment; flexible consultation and examination } \\
\text { times; conscious employer; patient navigator use. }\end{array}$ \\
\hline & $\begin{array}{l}\text { Motivation } \\
\text { to change }\end{array}$ & $\begin{array}{l}\text { People may not be motivated to change } \\
\text { their behaviors, for example by seeking } \\
\text { effective care for early detection. }\end{array}$ & $\begin{array}{l}\text { Dissemination of information designed to } \\
\text { motivate people to, for example, seek care or } \\
\text { undergo the recommended tests; use of financial } \\
\text { or material incentives; patient navigator use. }\end{array}$ \\
\hline
\end{tabular}


mammographs; improve the doctor-patient relationship with appropriate language and encouragement; demystifying the fear of the illness, of the diagnostic tests and of the treatment; make the employer aware; provide financial or material incentive; make use of the patient navigator ${ }^{14-22}$.

The patient navigator, a trained healthcare professional, facilitates the handling of patients in the healthcare system, helping them to overcome institutional, socioeconomic and personal barriers to healthcare access. Provides services such as scheduling diagnostic and follow-up appointments, facilitating referrals from the health system, and coordinates communication between patients and health professionals. This professional helps patients receive timely medical care and reduce care delays and missed follow-up rates ${ }^{25}$.

A program for early detection of breast cancer should be accepted by the public to assist with expected outcomes, such as $70 \%$ mammographic coverage rate, timely diagnosis and treatment, and reduced mortality rate. Adherence to the programs is associated with public motivation and awareness. The low awareness rate in most developing countries is alarming and interventions to raise public awareness are needed ${ }^{27}$.

\section{CONCLUSIONS}

The three contexts and the respective strategies identified in the most relevant literature which are applicable in Brazil are:

- organizational changes in the system: fostering leadership committed to the implementation of the guidelines, better governance of health services close to the target audience, flexible hours, patient navigation program and use of mobile mammographs, where appropriate;

- in the practice of health professionals: engagement of breast cancer specialists in primary care to optimize the training of health professionals and users;

- in the use of health services by users: national campaign for mass dissemination of guidelines involving multiple actors from the Ministry of Health, state and municipal health departments, civil and medical organizations.

\section{REFERENCES}

1. World Health Organization. Global status report on noncommunicable diseases 2014. Report. Genebra:WHO; 2014.

2. Liedke PE, Finkelstein DM, Szymonifka J, Barrios CH, Chavarri-Guerra Y, Bines J, et al. Outcomes of breast cancer in Brazil related to health care coverage: a retrospective cohort study. Cancer Epidemiol Biomarkers Prev. 2014;23(1):126-33. https://doi.org/10.1158/1055-9965.EPI-13-0693

3. Guerra MR, Silva GA, Nogueira MC, Leite IC, Oliveira RV, Cintra JR, et al. Breast cancer survival and health iniquities. Cad Saúde Pública. 2015;31(8):1673-84. http://dx.doi. org/10.1590/0102-311X00145214

4. Soares PB, Quirino Filho S, de Souza WP, Gonçalves RC, Martelli DR, Silveira MF, et al. Characteristics of women with breast cancer seen at reference services in the North of Minas Gerais. Rev Bras Epidemiol. 2012;15(3):595-604.

5. Balabram D, Turra CM, Gobbi H. Survival of patients with operable breast cancer (stages I-III) at a Brazilian public hospital: A closer look into cause-specific mortality. BMC Cancer. 2013;13:434. https://doi.org/10.1186/1471-2407-13-434

6. Silva RCF. Evidências científicas e análise comparada de programas de rastreamento: elementos para a discussão de pré-requisitos ao rastreamento organizado de câncer de mama no Brasil [tese]. Rio de Janeiro: Escola Nacional de Saúde Pública Sergio Arouca; 2012.

7. Peixoto JE. A trajetória da mamografia - à procura da qualidade [palestra]. In: Projeto História do Câncer - atores, cenários e políticas públicas. Rio de Janeiro: Fiocruz; 2012.

8. International Agency for Research on Cancer. IARC Handbooks of Cancer Prevention. Lyon: IARC Press; 2002. v. 7.

9. Teixeira LA, Porto MA, Noronha CP. O Câncer no Brasil: passado e presente. Rio de Janeiro: Outras Letras/FAPERJ; 2012.
10. Instituto Nacional de Câncer José Alencar Gomes da Silva. Diretrizes para a detecção precoce do câncer de mama no Brasil. Rio de Janeiro: INCA; 2015.

11. Fretheim A, Munabi-Babigumira S, Oxman AD, Lavis JN, Lewin S. SUPPORT Tools for Evidence-informed Policymaking in health 6: Using research evidence to address how an option will be implemented. Health Res Policy Syst. 2009;7(Supl. 1):S6. https://doi.org/10.1186/1478-4505-7-S1-S6

12. Lavis JN, Wilson MG, Oxman AD, Grimshaw J, Lewin S, Fretheim A. SUPPORT Tools for evidence-informed health Policymaking (STP) 5. Using research evidence to frame options to address a problem. Health Res Policy Syst. 2009;7(Supl. 1):S5. https://doi.org/10.1186/1478-4505-7-S1-S5

13. Silva V, Grande AJ, Martimbianco AL, Riera R, Carvalho AP. Overview of systematic reviews - a new type of study: part I: why and for whom? Sao Paulo Med J. 2012;130(6):398-404. https://doi.org/10.1590/s1516-31802012000600007

14. Baron RC, Rimer BK, Breslow RA, Coates RJ, Kerner J, Melillo $\mathrm{S}$, et al. Client-Directed Interventions to Increase Community Demand for Breast, Cervical, and Colorectal Cancer Screening. Am J Prev Med. 2008;35(1 Supl.):S34-55. https://doi. org/10.1016/j.amepre.2008.04.002

15. Baron RC, Rimer BK, Coates RJ, Kerner J, Kalra GP, Melillo $\mathrm{S}$, et al. Client-Directed Interventions to Increase Community Access to Breast, Cervical, and Colorectal Cancer Screening. Am J Prev Med. 2008;35(1 Supl.):S56-66. https://doi. org/10.1016/j.amepre.2008.04.001

16. Bowser D, Marqusee H, El Koussa M, Atun R. Health system barriers and enablers to early access to breast cancer screening, detection, and diagnosis: a global analysis applied to the MENA region. Public Health. 2017;152:58-74. https://doi. org/10.1016/j.puhe.2017.07.020 
17. Lu M, Moritz S, Lorenzetti D, Sykes L, Straus S, Quan H. A systematic review of interventions to increase breast and cervical cancer screening uptake among Asian women. BMC Public Health. 2012;12:413. https://doi.org/10.1186/1471-2458-12-413

18. Peterson EB, Ostroff, JS, DuHamel KN, D’Agostino TA, Hernandez M, Canzona MR, et al. Impact of providerpatient communication on cancer screening adherence: A systematic review. Prev Med. 2016;93:96-105. https://doi. org/10.1016/j.ypmed.2016.09.034

19. Sabatino SA, Lawrence B, Elder R, Mercer SL, Wilson KM, DeVinney B, et al. Effectiveness of interventions to increase screening for breast, cervical, and colorectal cancers: nine updated systematic reviews for The Guide to Community Preventive Services. Am J Prev Med. 2012;43(1):97-118. https:// doi.org/10.1016/j.amepre.2012.04.009

20. Spadea T, Bellini S, Kunst A, Stirbu I, Costa G. The impact of interventions to improve attendance in female cancer screening among lower socioeconomic groups: a review. Prev Med. 2010;50(4):159-64. https://doi.org/10.1016/j.ypmed.2010.01.007

21. Community Preventive Services Task Force. Cancer Screening: Multicomponent Interventions-Breast Cancer [Internet]. 2016 [acessado em 6 mar. 2017]. Disponível em: https:// www.thecommunityguide.org/findings/cancer-screeningmulticomponent-interventions-breast-cancer
22. Uy C, Lopez J, Trinh-Shevrin C, Kwon SC, Sherman SE, Liang PS. Text Messaging Interventions on Cancer Screening Rates: A Systematic Review. J Med Internet Res. 2017;19(8):e296. https://doi.org/10.2196/jmir.7893

23. Ohl IC, Ohl RI, Chavaglia SR, Goldman RE. Public actions for control of breast cancer in Brazil: integrative review. Rev Bras Enferm. 2016;69(4):746-55. http://dx.doi.org/10.1590/0034$7167.2016690424 \mathrm{i}$

24. Harford J, Azavedo E, Fischietto M. Guideline implementation for breast healthcare in low- and middle-income countries: breast healthcare program resource allocation. Cancer. 2008;113(8 Supl.):2282-96. https://doi.org/10.1002/cncr.23841

25. Bukowski A, Gioia S, Chavarri-Guerra Y, Soto-Perez-deCelis E, St Louis J, Paulino E, et al. Patient Navigation to Improve Access to Breast Cancer Care in Brazil. J Glob Oncol. 2016;3(5):433-437. https://doi.org/10.1200/JGO.2016.006726

26. Gioia S. Why is breast cancer early detection important? Mastology. 2017;27(3):173-5. https://doi.org/10.5327/ Z259453942017EDIT273

27. Hone T, Rasella D, Barreto M, Atun R, Majeed A, Millett C. Large reductions in amenable mortality associated with Brazil's primary care expansion and strong health governance. Health Aff (Millwood). 2017;36(1):149-58. https://doi.org/10.1377/ hlthaff.2016.0966 